\title{
Source identification for situational awareness of the August 24 2016 Central Italy event
}

\author{
CHRISTIAN BIGNAMI*, CRISTIANO TOLOMEI, GIUSEPPE \\ PEZZO, FrANCESCO GUGLIELMINO, SiMONE ATZORI, \\ ELISA TRASATTI, ANDREA ANTONIOLI, SALVATORE \\ STRAMONDO, STEFANO SALVI (1) \\ (1) Istituto Nazionale di Geofisica e Vulcanologia \\ *christian.bignami@ingv.it
}

\begin{abstract}
On August 24, 2016, at 01:36 UTC a ML 6.0 earthquake struck a portion of the Central Apennines between the towns of Norcia and Amatrice. The epicentre was located near the town of Accumoli. Prompt Synthetic Aperture Radar (SAR) acquisitions and the available scientific knowledge of the area allowed to elaborate a first interpretative framework of the ongoing seismic sequence only 30 hours after the mainshock and a second analysis, complete of several Interferometric SAR (InSAR) data within two weeks. Through the inversion of InSAR data, we found that the seismogenic structure is oriented NNW-SSE and extends about $20 \mathrm{~km}$ between the towns of Norcia and Amatrice with a width of about $10 \mathrm{~km}$. The retrieved slip reaches a maximum value of more than $1.2 \mathrm{~m}$, and stops at a depth of about $4 \mathrm{~km}$. Preliminary fault slip inversions suggest two main patches of co-seismic deformation located NW and SE of the hypocenter.
\end{abstract}

\section{INTRODUCTION}

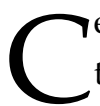
entral Apennines are known to be one of the most seismically hazardous area in Italy

[http://zone-

sismiche.mi.ingv.it/mappa_ps_apr04/italia.html]. The region surrounding the Monti della Laga, was struck by several earthquakes in historical times. In 1627 and 1639, the area was affected by two events with estimated magnitudes of about 5.3 and 6.2 respectively. A century later, in 1672, another Mw 5.3 hit the same area, followed in 1703 by a strong event of magnitude higher than 6 [Rovida et al., 2016]. The $24^{\text {th }}$ of August 2016, at 01:36 UTC an Mw 6.0 earthquake hit an extensive portion of this area. 
The epicentre is located near the village of Accumoli, between the towns of Norcia and Amatrice, at a depth of $8.0 \pm 0.2 \mathrm{~km}$.

The mainshock was followed by an M 5.3 earthquake at 02:33 UTC, about $12 \mathrm{~km} \mathrm{NW}$ from the first event, and it was the only $M>5$ aftershock registered. The aftershocks sequence evolved mainly to the NW towards Norcia and the Sibillini Mountains.

In this paper, we show the scientific productions obtained during the emergency phase. A first report was sent to the DPC (Italian Civil Protection Department) the $25^{\text {th }}$ of August (doi: 10.5281/zenodo.60938, in Italian). As soon as new SAR (Synthetic Aperture Radar) images from COSMO-SkyMed (CSK) and Sentinel-1A (S1A) became available, prompt data analysis and new fault inversions led to model InSAR (Interferometric SAR) images, with different Line of Sight (LOS) and orbits, producing a robust slip distribution just fourteen days after the mainshock.

\section{FIRST INSAR RESULTS}

The first post-event SAR image was acquired the 24/08/16 by ALOS-2 (L-band instrument of the Japan Aerospace Exploration Agency, JAXA). The first InSAR (Interferometric SAR) analysis was performed considering three preevent $(01 / 07 / 15,09 / 09 / 15,27 / 01 / 16)$ and one post event (24/08/16) ALOS-2 satellite acquisitions.

The authors want to thank ASI for providing COSMO-SkyMed data during the emergency and ESA for furnishing Sentinel-1B images even if the satellite is still in commissioning phase.
Among the three co-seismic interferograms, the most coherent and with minimum atmospheric influences, is the 09/09/15-24/08/16 (Id- 1 , Table 1). Even if it includes the effects of all the seismicity encompassing the period, most of the deformation is due to the Mw 6.0 mainshock (24/08/16 1:36 UTC) and possibly the Mw 5.3 greatest aftershock (24/08/16 2:33 UTC). The measured surface displacement field was subsequently modelled in a first instance by means of a non-linear inversion providing the parameters (strike, dip, and rake) for a uniform slip fault plane. The heterogeneous slip was then obtained, by using a linear inversion algorithm exploiting the fault parameters previously obtained [e.g., Atzori et al., 2009] and a preliminary model of the seismogenic fault was already released the day after the mainshock (doi: 10.5281/zenodo.60938).

\section{INSAR ANALYSIS AND FAULT MODELLING}

The InSAR analysis benefitted of a large number of multi-frequency images from different satellites having different characteristics and spatial resolutions: ALOS-2 (JAXA) operating at L-band, S1A (from the European Program Copernicus) at C-band, CSK (Agenzia Spaziale Italiana, ASI), at X-band. The European Space Agency (ESA) also provided Sentinel-1B (S1B) data (the twin satellite of S1A, with the same sensor on board), although the satellite was still in the commissioning phase, and therefore not fully operative. With S1A and S1B images we were able to process cross-interferometric pairs, with a temporal baseline of 6 days only (respect to the 12 days revisiting time of the single satellite). Table 1 shows the resulting co-seismic interferometric SAR pairs and the sensors' main 
Table 1: Co-seismic interferometric pairs available and processed. S1 is Sentinel-1, CSK is Cosmo-SkyMed. IWS means Interferometric Wide Swath.

\begin{tabular}{|c|c|c|c|c|c|c|c|}
\hline Id & Sensor & $\begin{array}{l}\text { Acquisition } \\
\text { mode }\end{array}$ & $\begin{array}{c}\text { Interferometric } \\
\text { Pair }\end{array}$ & $\begin{array}{l}\text { Wavelength } \\
{[\mathrm{cm}]}\end{array}$ & $\begin{array}{c}\text { Perpendicular } \\
\text { baseline }[\mathrm{m}]\end{array}$ & Orbit & $\begin{array}{c}\text { Incidence } \\
\text { angle } \\
\text { [deg] }\end{array}$ \\
\hline Id-1 & ALOS-2 & StripMap & $\begin{array}{l}09092015 \\
24082016\end{array}$ & 23.6 & -198 & Ascending & 36.6 \\
\hline Id-2 & S1 & IWS & $\begin{array}{l}20082016 \\
26082016\end{array}$ & 5.56 & 105 & Descending & 39 \\
\hline Id-3 & S1 & IWS & $\begin{array}{l}21082016 \\
27082016\end{array}$ & 5.56 & 79 & Descending & 39 \\
\hline Id-4 & S1 & IWS & $\begin{array}{l}15082016 \\
27082016\end{array}$ & 5.56 & 32 & Ascending & 39 \\
\hline Id-5 & CSK & StripMap & $\begin{array}{l}20082016 \\
28082016\end{array}$ & 3.1 & 101 & Descending & 30.6 \\
\hline Id-6 & S1 & IWS & $\begin{array}{l}22082016 \\
28082016\end{array}$ & 5.56 & -29 & Ascending & 39 \\
\hline Id-7 & ALOS2 & StripMap & $\begin{array}{l}25052016 \\
31082016\end{array}$ & 23.6 & 88 & Descending & 32.9 \\
\hline
\end{tabular}

characteristics, while some of the calculated interferograms are shown in Figure 1.

All the interferograms were unwrapped to retrieve the deformation field caused by the earthquake. The resulting displacement maps from all these interferograms show very similar patterns, characterised by a maximum displacement value of about $20 \mathrm{~cm}$ away from the respective sensor LOS. Note that the incidence angle of the data is similar for all the available data, apart from the different orbits. To estimate 3D surface displacement maps, we applied the
SISTEM (Simultaneous and Integrated Strain Tensor Estimation from geodetic and satellite deformation Measurements) method [Guglielmino et al., 2011a] to the available co-seismic GPS [INGV Working Group "GPS Geodesy", 2016] and to three InSAR data with the wider spatial coverage of the epicentral area. In particular, we used the two S1 (ascending and descending) and the descending ALOS-2 InSAR data, reported in Table 1 with Id-3, Id-4, and Id7 , respectively. The SISTEM's outputs are reported in Figure 2. 


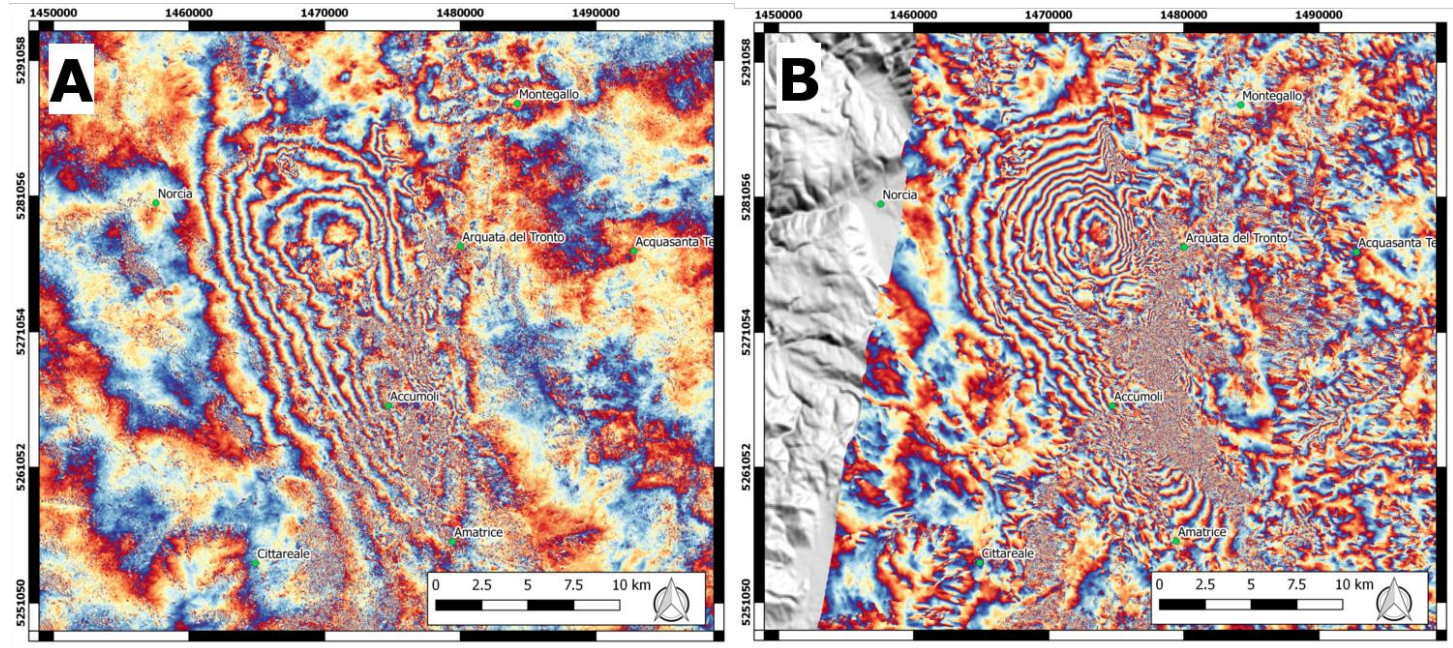

Figure 1. Examples of InSAR wrapped maps from: A) S1 ascending pair (Id-4 in Table 1); B) CSK interferograms.

Surface deformations revealed by SISTEM, show a predominant vertical deformation pattern $(2$ to 3 times higher than the horizontal ones) with a maximum value of $-0.25 \mathrm{~m}$. Thanks to these 3D maps, it would be - hopefully - possible to identify further structures activated during the seismic sequence.
The vertical component confirms the surface subsidence with the typical "spoon" shape, as already observed in past earthquakes in the Apennine (e.g., Mw 6.3 L'Aquila earthquake, 2009). It extends for about $20 \mathrm{~km}$ along the NNW-SSE direction. The maximum displacement value is in correspondence of the town of Accumoli.
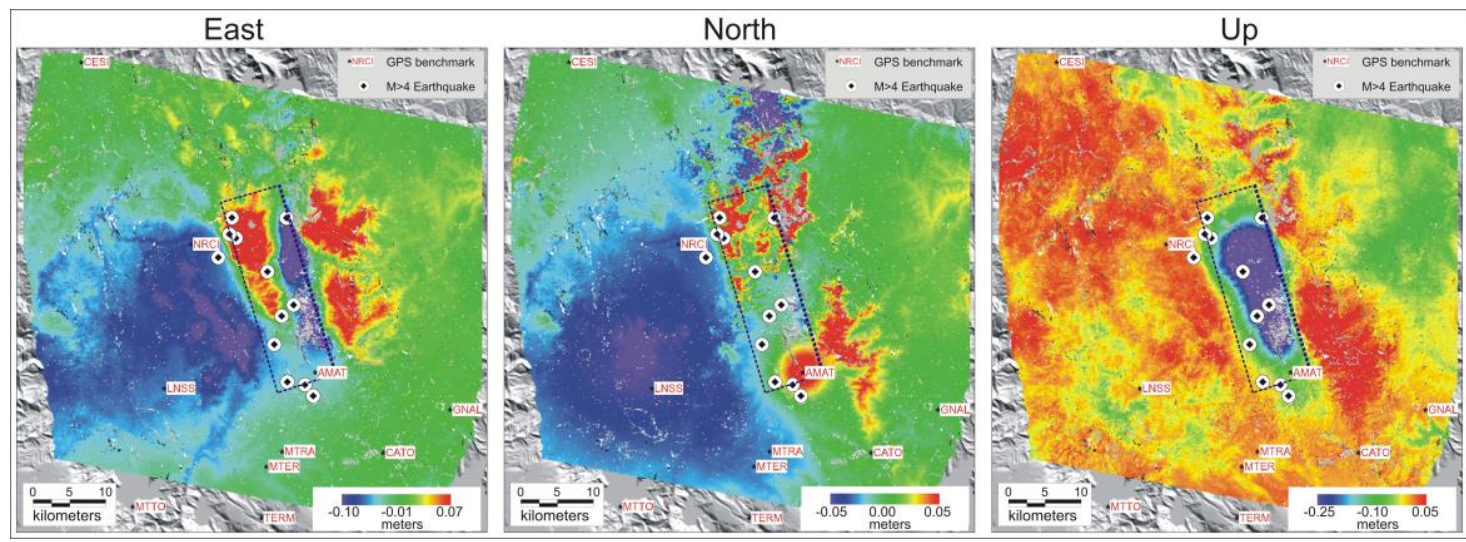

Figure 2. SISTEM results: East, North, and Up components of the displacement field are reported, respectively. The dashed box refers to the inverted fault plain. 

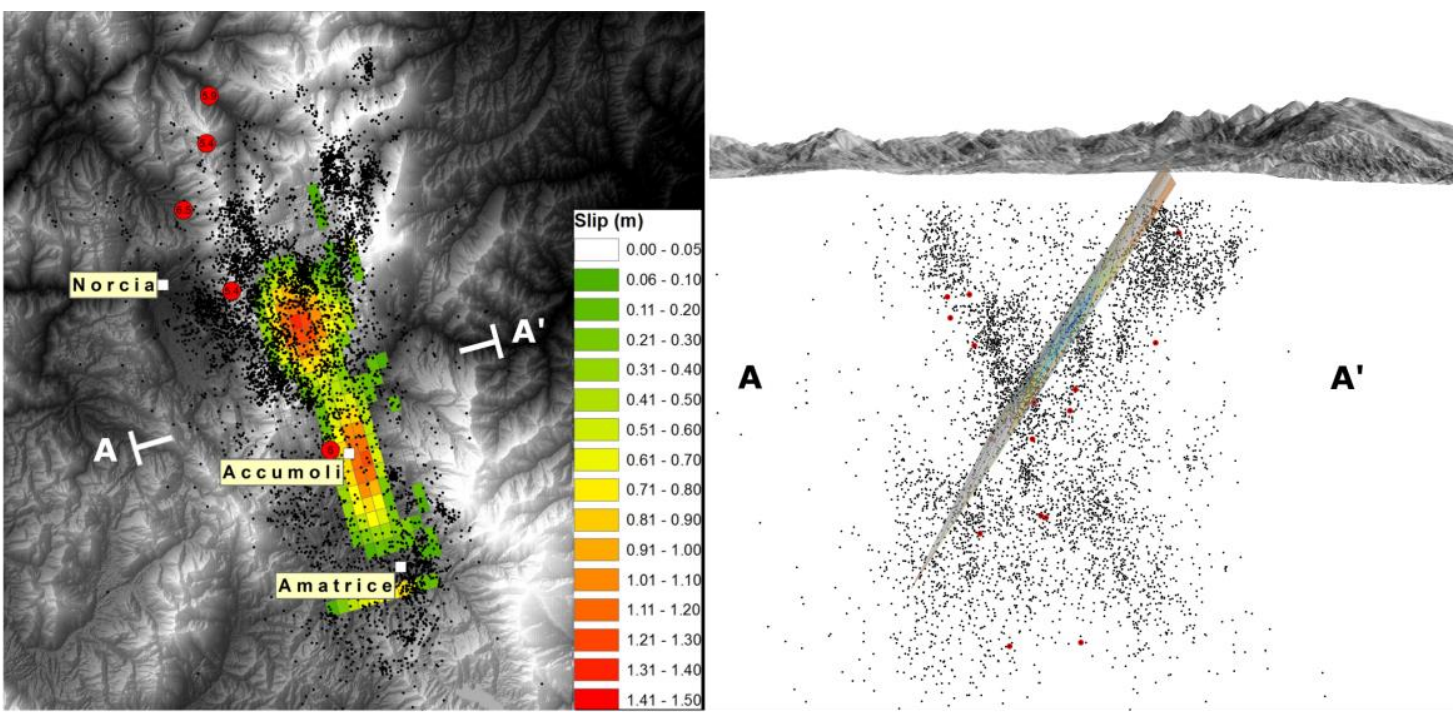

Figure 3. Modelling results. a) Co-seismic fault slip distribution from the InSAR data modelling. The mainshock and the M 5.3 aftershock are reported with the red pentagon, while the $M<5$ aftershocks are shown with black dots. b) $3 D$ view of the fault below the topographic surface. The view is from SSE along the strike direction (SSE-NNW, section $A-A^{\prime}$ in panel (a)). The red dots are the largest events $(M \geq 4)$ and black dots are the $M<4$ aftershocks.

With respect to the first report, a new solution was delivered after all the interferograms listed in Table 1 were processed. InSAR data used in the inversion procedure consist of about 19500 measurements obtained by sampling 5 unwrapped interferograms (Id-1, Id-3, Id-4, Id-5, and Id-7 in Table 1) and 107 measurements from the CGPS [INGV Working Group "GPS Geodesy", 2016; Cheloni et al., 2016]. The results of such inversion are shown in Figure 3. The retrieved source model consists of a fault plane oriented NNW-SSE. The slip spans an area of about $20 \mathrm{~km}$ length, and a width of $10 \mathrm{~km}$, and stops at a depth of about $4 \mathrm{~km}$. This area is located between the towns of Norcia and Amatrice. The fault slip is characterised by two main patches, one located between Amatrice and Accumoli, and one between Accumoli and Norcia. The maximum slip values are about $1 \mathrm{~m}$ for both patches. Note that a relatively large slip is also present in the southern part of the fault plane, and it is associated to some uncertainties on the data. Comparison of the fault plane with the relocated aftershocks distribution [Michele et al., 2016] shows a good agreement between the structures constrained by the two different analysis. Note that, in this preliminary result, two main patterns of seismicity are visible. One pattern is approximately laying around the fault plane, while a second one seems identify an antithetic fault East of Norcia village. The last feature is still under investigation.

In order to show how the slip of the mainshock modified the stress loading of the region, we computed the Coulomb Failure Function [CFF, e.g., Harris et al., 1998] on nearby fault planes as listed in the DISS [DISS Working Group, 2010] data-base. In particular, we imaged the 


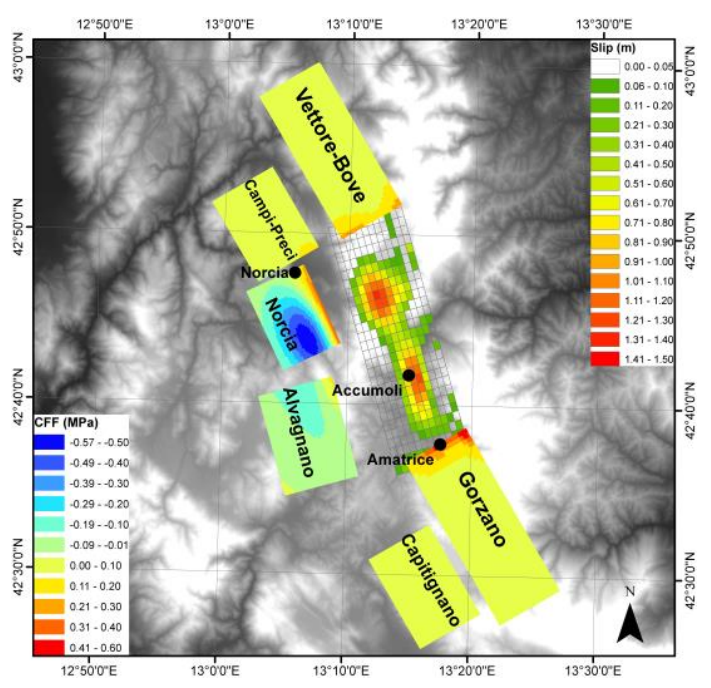

Figure 4. CFF computations on the known faults nearby the Amatrice fault. The stress variations are due to the mainfault slip distribution.

CFF values on six fault planes surrounding the mainshock. Positive CFF variations can promote subsequent slip on adjacent faults, while negative CFF values in principle inhibit it.

Our results show a decrease of CFF value on the fault planes West of the main fault, while a positive increment of its value is present on the two planes aligned with the Amatrice fault. In particular, a value relatively high compared with the mean stress drop on an earthquake of this size, is present in the northern portion of the Gorzano fault.

\section{CONCLUSION}

We showed how, during the emergency phase of an earthquake, the use of InSAR geodetic data and their inversion for seismic source retrieval can play an important role for supporting civil protection authorities. The prompt availability of a large dataset of SAR images and the fast deliver of displacement modelling and fault slip distribution demonstrated that InSAR, thanks to the present day SAR constellation (S1, CSK, ALOS-2, etc.) can rapidly issue scientific information.

A quite robust solution of InSAR data inversion was provided only few hours after the main event. Indeed, thanks to ALOS-2 data, the INGV team responsible for the analysis of the geodetic data was able to process and deliver a first seismic source model just one day after the mainshock occurrence. This first estimation was improved few days later, when additional SAR images, acquired at different wavelengths and different viewing geometries, allowed to better constrain the fault parameters. The new fault model substantially confirmed the reliability of the first estimation, adding more details about the slip values and fault patches dislocation. Furthermore, it confirms the agreement with the fault plane imaged by means of relocated aftershocks.

\section{REFERENCES}

Atzori, S., I. Hunstad, M. Chini, S. Salvi, C. Tolomei, C. Bignami, S. Stramondo, E. Trasatti, A. Antonioli, and E. Boschi (2009). Finite fault inversion of DInSAR coseismic displacement of the 2009 L'Aquila earthquake (central Italy), Geophys. Res. Lett., 36, L15305, doi:10.1029/2009GL039293.

Cheloni, D., Serpelloni, E., Devoti, R., D’Agostino, N., Pietrantonio, G., Riguzzi, F., Anzidei, M., Avallone, A., Cavaliere, A., Cecere, G., D'Ambrosio, C., Esposito, A., Falco, L., Galvani, A., Selvaggi, G., Sepe, V., Calcaterra, S., Giuliani, R., Mattone, M., Gambino, P., Abruzzese, L., Cardinale, V., Castagnozzi, A., De Luca, G., 
Massucci, A., Memmolo, A., Migliari, F., Minichiello F., and Zarrilli, L., (2016). GPS observations of coseismic deformation following the 2016, August 24, Mw 6 Amatrice earthquake (central Italy): data, analysis and preliminary fault model. Annals of Geophysics, vol. 59, Fast Track 5, 2016, DOI: 10.4401/AG-7269, in press. Guglielmino, F., Nunnari, G., Puglisi, G., Spata, A. (2011). Simultaneous and Integrated Strain Tensor Estimation from geodetic and satellite deformation Measurements (SISTEM) to obtain three-dimensional displacement maps. IEEE Trans. Geosci. Remote Sens. vol. 49, 1815-1826. doi:10.1109/TGRS.2010.2103078.

Harris, R. (1998). Introduction to special section: stress triggers, stress shadows, and implications for seismic hazard. J. Geophys. Res. 103, 24347-24358.

INGV Working Group "GPS Geodesy (GPS data and data analysis center)" (2016). Preliminary co-seismic displacements for the August
24, 2016 ML6, Amatrice (central Italy) earthquake from the analysis of continuous GPS stations, DOI:10.5281/zenodo.61355.

Michele M., Di Stefano R., Chiaraluce L., Cattaneo M., De Gori P., Monachesi G., Latorre D., Marzorati S., Valoroso L., Ladina C., Chiarabba C., Lauciani V., Fares M., The Amatrice 2016 seismic sequence: a preliminary look to the mainshock and aftershocks distribution, Annals of Geophysics Fast Track, in preparation.

Rovida A., Locati M., Camassi R., Lolli B., Gasperini P. (2016). CPTI15, the 2015 version of the Parametric Catalogue of Italian Earthquakes. Istituto Nazionale di Geofisica e Vulcanologia. doi:http://doi.org/10.6092/INGV.IT-CPTI15. Working Group, DISS (2010). Database of Individual Seismogenic Sources (DISS), Version 3.1.1: a compilation of potential sources for earthquakes larger than M 5.5 in Italy and surrounding areas. http://diss.rm.ingv.it/diss/. 